\title{
Enhancement of laser heating process by laser surface modification on Titanium alloy
}

\author{
A. Q. Zaifuddin*, F. Zulhilmi, M. H. Aiman, M. M. Quazi, M. Ishak \\ Joining, Welding and Laser Processing (JWL) Lab, Faculty of Mechanical and Automotive Engineering, Universiti Malaysia Pahang, 26600 Pekan, \\ Pahang, Malaysia \\ Phone: +6094246216
}

\begin{abstract}
Titanium alloys are widely utilized in laser heating applications. However, it has poor optical properties due to low laser energy absorption. Nevertheless, a higher energy absorption can be realized by modifying the surface profile through increasing the surface roughness. In this present work, the laser surface modification (LSM) process was carried out to increase the roughness on surface of Ti6Al4V titanium alloy. Subsequently, the surface characterization and surface roughness were analysed by using the 3D optical microscope. The effect of laser power on the increment of surface roughness was investigated. It was revealed that an increase in laser power during LSM process could increase the surface roughness. The result shows that, the surface roughness of titanium alloy increased 27 times when modified with the highest laser power (27W) compared to the gritted surface. Furthermore, the modified surface by LSM will be heated using laser radiation in order to analyse the effect of surface roughness towards laser heating temperature. Depending on the value of the power during laser heating, the maximum temperature measured could be increased $27 \%$ corresponding to a gritted flat reference surface.
\end{abstract}

ARTICLE HISTORY

Received: 14th Feb 2021

Revised: $08^{\text {th }}$ July 2021

Accepted: $15^{\text {th }}$ Aug 2021

\section{KEYWORDS}

Laser surface modification; surface roughness;

Titanium alloy.

\section{INTRODUCTION}

Due to high strength, excellent corrosion resistance, and low density, titanium alloys have received much attention in recent years by utilizing laser heating process for related applications, especially in biomedical, aerospace, and aircraft [1-3]. However, due to its high reflectivity, titanium alloys also possess some difficulties when dealing with laser. It has been reported that its absorption is only 30\% [4] and thus, wasting the remaining laser energy towards the ambient instead of contributing to the process. Consequently, a high laser power is required to compensate for the low energy efficiency of the process.

Nevertheless, many attempts to counter the issues regarding material's optical properties have been made and it was found that when modifying the surface layer, the laser energy absorptivity can be increased [5, 6]. By producing micro or nanoscale grooves, dimples, or random patterns on the surface layer, it is possible to scatter the laser energy over larger surface areas and increase the material's absorption.

Therefore, many approaches for preparing the surface have been studied, such as chemical etching, electrochemical machining (ECM), and laser surface modification (LSM). Among these methods, LSM owns several advantages. For instance, the chemical and ECM etching processes are accompanied by chemical work, which adversely affects the environment [7]. Besides, in terms of processing time, LSM is considered as extremely fast process which allows short processing times $[8,9]$. For instance, LSM process consumes a much shorter time than chemical etching since the latter required more procedures [10]. Additionally, LSM also owns a unique advantage which is the capability of fabricating surface texture with high complexity and accuracy $[11,12]$. Due to these merits, LSM has been widely used on different materials including titanium, stainless steel, ceramic and tungsten carbide [13]. Hence, LSM is regarded as a more efficient, precise, and versatile approach compared to other surface modification methods.

Based on the mentioned advantages of the LSM process, it would be wise to observe its benefit in enhancing laser energy absorption for the laser material process in terms of maximum temperature. Hence, in this research, the surface of the titanium alloy is modified using LSM. The effect of LSM laser power on the surface roughness of titanium alloy were studied. Besides, the effect of surface roughness towards the heating temperature during laser heating process was also investigated. 


\section{MATERIALS AND METHODS}

Material

The experimental works involved Ti6Al4V, a grade 5 titanium alloy rod with a diamension of $6 \mathrm{~mm}$ and $6 \mathrm{~mm}$ height. Next, Table 1 presents the chemical composition while the mechanical properties of the titanium alloy can be seen in Table 2.

Table 1. Mechanical properties of titanium alloy Ti6Al4V

\begin{tabular}{cc}
\hline Properties & Ti6Al4V \\
\hline Melting point & $1600^{\circ} \mathrm{C}$ \\
Hardness Vickers & $60 \mathrm{HV}$ \\
Thermal conductivity & $6.7 \mathrm{~W} / \mathrm{mK}$ \\
\hline
\end{tabular}

Table 2. Chemical composition of Ti6Al4V

\begin{tabular}{ccccccccc}
\hline Elements & $\mathrm{Ti}$ & $\mathrm{Fe}$ & $\mathrm{Al}$ & $\mathrm{V}$ & $\mathrm{C}$ & $\mathrm{O}$ & $\mathrm{N}$ & $\mathrm{H}$ \\
\hline$(\mathrm{wt} \%)$ & The rest & $<0.30$ & $5.50-6.75$ & $3.50-4.50$ & $<0.01$ & $<0.20$ & $<0.10$ & $<0.01$ \\
\hline
\end{tabular}

\section{Process Flow}

The experimental work, as shown in Figure 1, starts with material pre-processing where the as-received samples are manually ground. Next, the gritted surface will be modified with different power of LSM parameters. Afterwards, the surface modified samples proceed to the surface characterization process. In the following, the results of the samples pre and post LSM will be discussed. This lays the foundation for analyzing the effect of LSM on surface roughness of the titanium alloy. Further, the modified samples were heated by another laser machine. The power of laser heating was also varied. The result obtained from this process is the temperature profile measured by an infrared thermometer. Further details regarding the experimental works will be discussed in the following sections below.

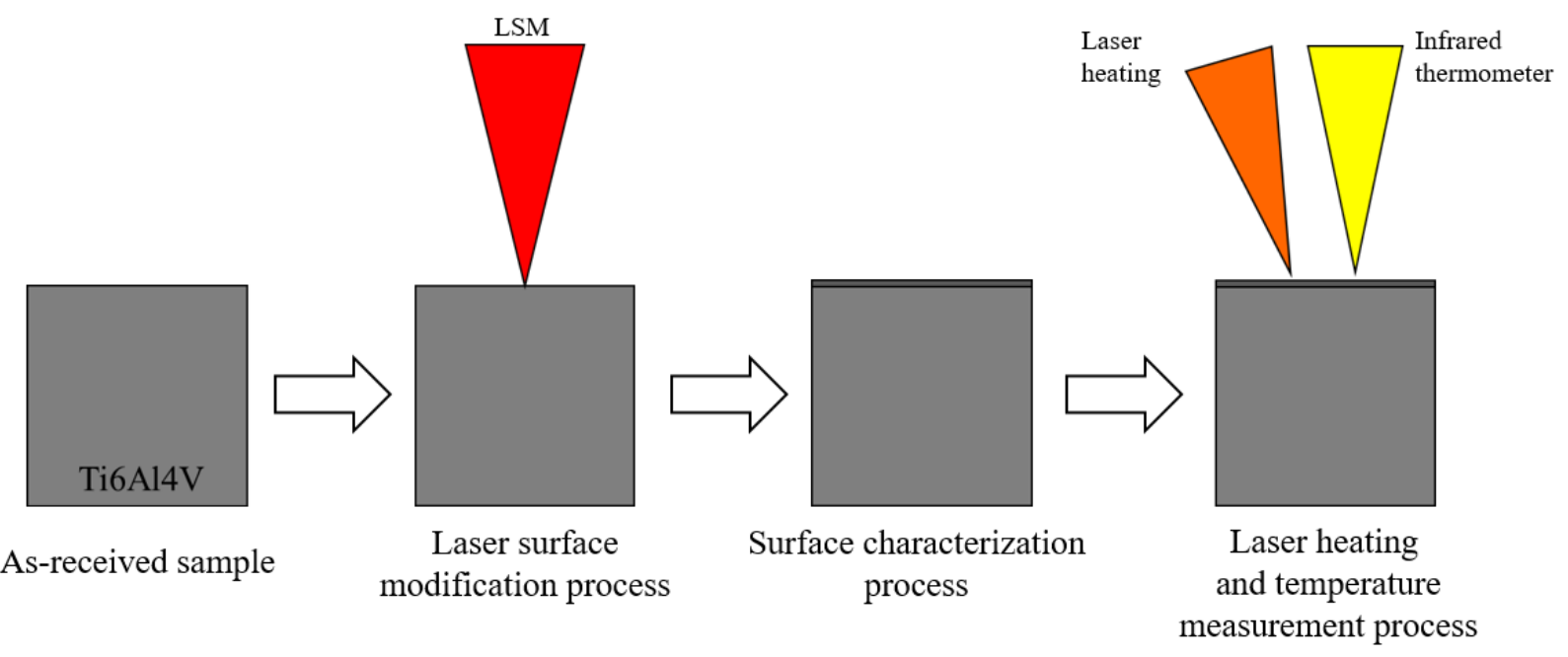

Figure 1. Process flow of experimental works

\section{Sample Preparation}

Initially, the titanium alloy surface, which will be laser modified, was roughly ground manually using silicon carbide grits $320 \mu \mathrm{m}$ diameter. Afterward, the titanium alloy will be cleansed using acetone to degrease any contaminants that might have been present on the samples. The gritted samples will then proceed to the next procedure, laser surface modification. 


\section{Laser Surface Modification}

The laser surface modification experiment was conducted using a fiber laser marking machine, Herolaser ML-MFA01 IPG, with a maximum of $30 \mathrm{~W}$ peak power. The machine was operated in pulse wave mode. The titanium alloy's gritted surface was modified with hatched parallel lines, which has a $0.001 \mathrm{~mm}$ distance between them. The setup for the LSM process can be seen in Figure 2. Furthermore, the laser power's focal length, scan speed, and pulse frequency were kept fixed, while the laser power was varied throughout the experiment from 9 Watt to 27 Watt. The laser input variables for LSM are shown in Table 3.

Table 3. Parameter setup for laser surface modification experiment

\begin{tabular}{cc}
\hline Laser specification & Parameter \\
\hline Operational mode & Pulse wave \\
Focal length $(\mathrm{mm})$ & 19.2 \\
Beam diameter $(\mathrm{mm})$ & 0.05 \\
Hatching distance $(\mathrm{mm})$ & 0.001 \\
Pulse frequency $(\mathrm{kHz})$ & 10 \\
Scanning speed $(\mathrm{mm} / \mathrm{s})$ & 500 \\
Laser power $(\mathrm{W})$ & 9,18, and 27 \\
\hline
\end{tabular}
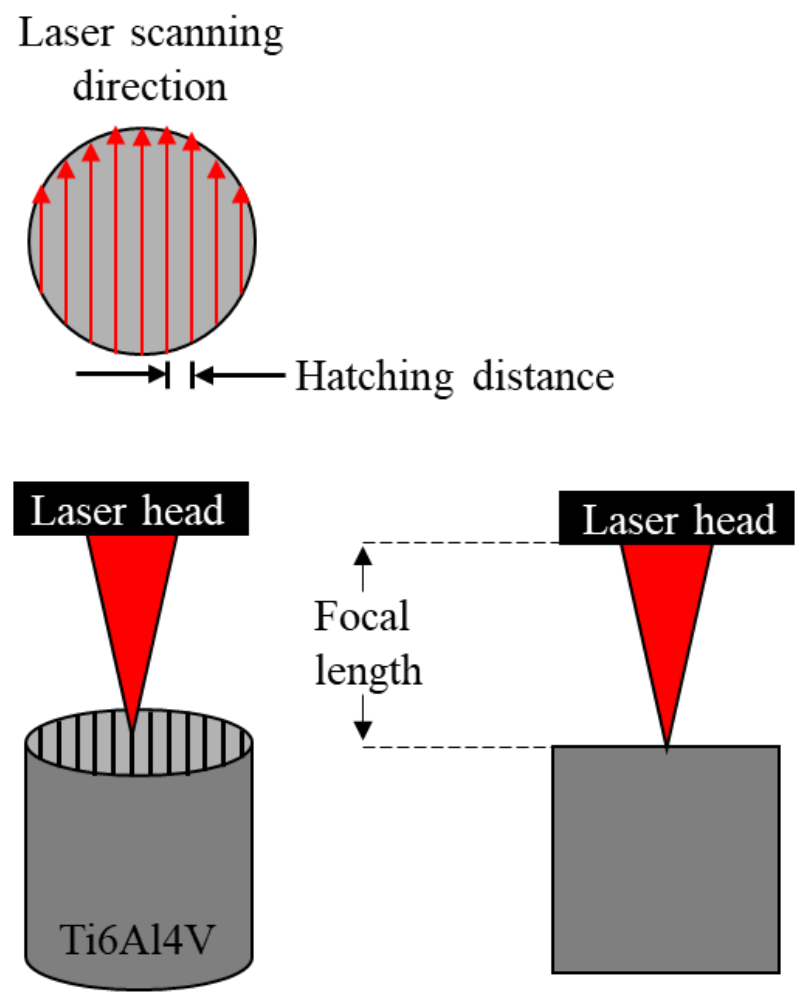

Figure 2. Laser surface modification setup

\section{Surface Characterization}

Upon modifying the surface by using the LSM method, the textured surface was analyzed according to the areal roughness (SA). Areal roughness is one of roughness properties which can be defined as the average roughness over the characterized area. The areal roughness of the samples were measured by using an OLS5000 3D measuring laser microscope from Olympus with 20X magnification. The area characterized was set to $648 \mu \mathrm{m}$ x $646 \mu \mathrm{m}$ throughout the surface analysis. 


\section{Laser Heating and Temperature Measurement}

Following surface characterization, the modified surface of the titanium rod was heated by employing laser radiation in ambient temperature. The laser heating experiment was conducted using IPG YLM 200/2000 fiber laser machine with a maximum available laser power of 200 Watt. The laser was operated in continuous wave mode. Besides, the angle of laser irradiation was set to $18^{\circ}$ for the safety of the lens. Process parameters such as laser power, focal length, and heating duration can be referred to in Table 4 . An alumina board was placed under the titanium rod to minimize heat conductivity.

During the laser heating process, the temperature was measured simultaneously using an infrared thermometers CTLM2HSF300-C3 from Micro-Epsilon. It is worth to note that the device can only measure temperature starting from $385^{\circ} \mathrm{C}$ up to $1600{ }^{\circ} \mathrm{C}$. The laser and infrared beam were placed $3 \mathrm{~mm}$ away from each other. Both beams were placed in such way in order to prevent spot overlap which could cause disturbance during temperature measurement. The schematic diagram of the laser heating and temperature measurement processes are shown in Figure 3.

Table 4. Parameter setup for laser heating experiment

\begin{tabular}{cc}
\hline Laser specification & Parameter \\
\hline Operational mode & Continuous wave \\
Focal length $(\mathrm{mm})$ & 120 \\
Heating duration $(\mathrm{s})$ & 60 \\
Laser power $(\mathrm{W})$ & 100,120 and 140 \\
\hline
\end{tabular}

(a)

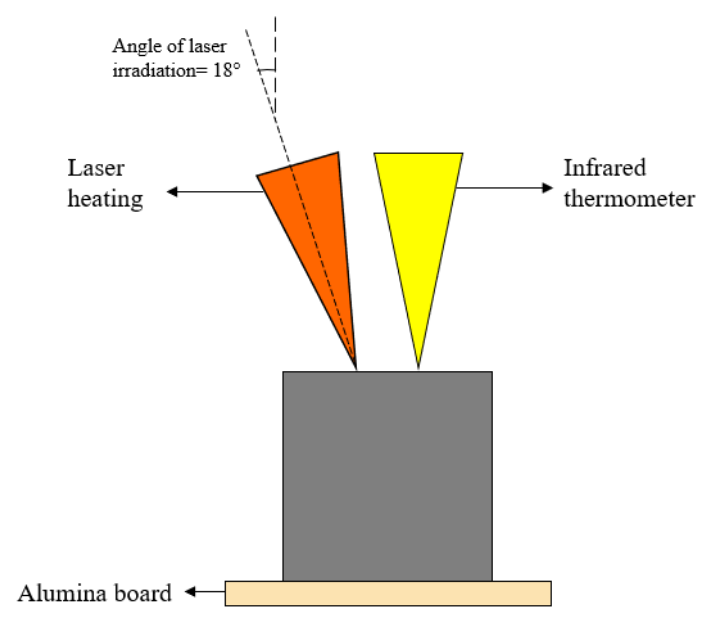

(b)

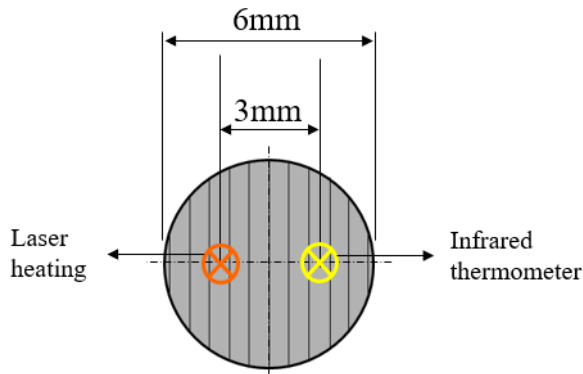

Figure 3. Laser heating and temperature measurement setup: (a) front view and (b) top view

\section{RESULTS}

\section{Gritted Surface}

After grinding the titanium alloy, the surface roughness was measured. Table 5 shows the height and optical image of the ground surface during material preparation. The sub-micron marks left by mechanical grinding on the surface of the samples can be seen. Nevertheless, this ground surface of titanium alloy can be considered as relatively flat surface since the areal roughness is approximately $0.124 \mu \mathrm{m}$. 
Table 5. Surface topography of gritted surface with dimension of $648 \mu \mathrm{m} \times 646 \mu \mathrm{m}$

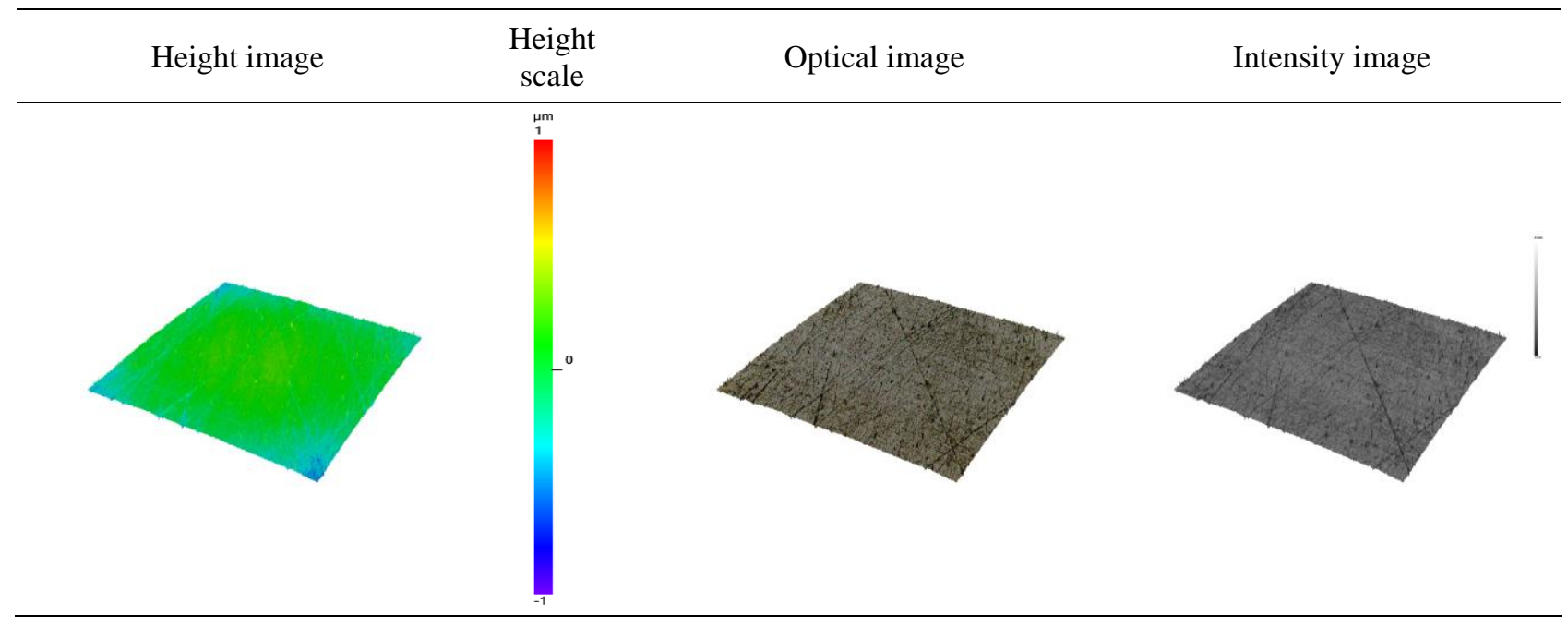

\section{Effect of Laser Power on Surface Roughness}

Table 6 shows images of the modified surface structures as a function of laser power. Due to variations in the laser parameters' power, the changes in surface topography can be seen clearly. High power input generates a new surface texture that was predominantly following the scan direction but with a more chaotic pattern as shown in the 3D figures.

From the tabulated data in Table 5, the result's trend can be seen in the graph in Figure 4. It shows that the roughness properties of the surface increase with increasing laser power. According to the trend of the graph, it should be noted that the surface roughness increases 27 times when radiated with the highest laser power (27W) compared to the gritted surface. This was because a high laser power able to supply more heat energy during the process. A massive amount of heat energy from higher laser power could remove more material from the titanium alloy surface. When the material removal increases, it creates more microgrooves, which will change the surface's texture and, hence, increase the surface roughness.

It can be supported by the finding from A Sulaiman, who reported that when a higher laser power usage is applied to modify the metal's surface, bigger and deeper microgrooves will be produced hence, increasing the surface roughness [14]. Besides, the increment in laser power was attributed to the increase in energy radiated will also affect the melt pool homogeneity and size, inducing larger melt tracks, hence producing rough surface [15]. Moreover, the increment of energy supply during high laser power could create a large diameter spot size that will increase the overlapping percentage and increase surface roughness [16].

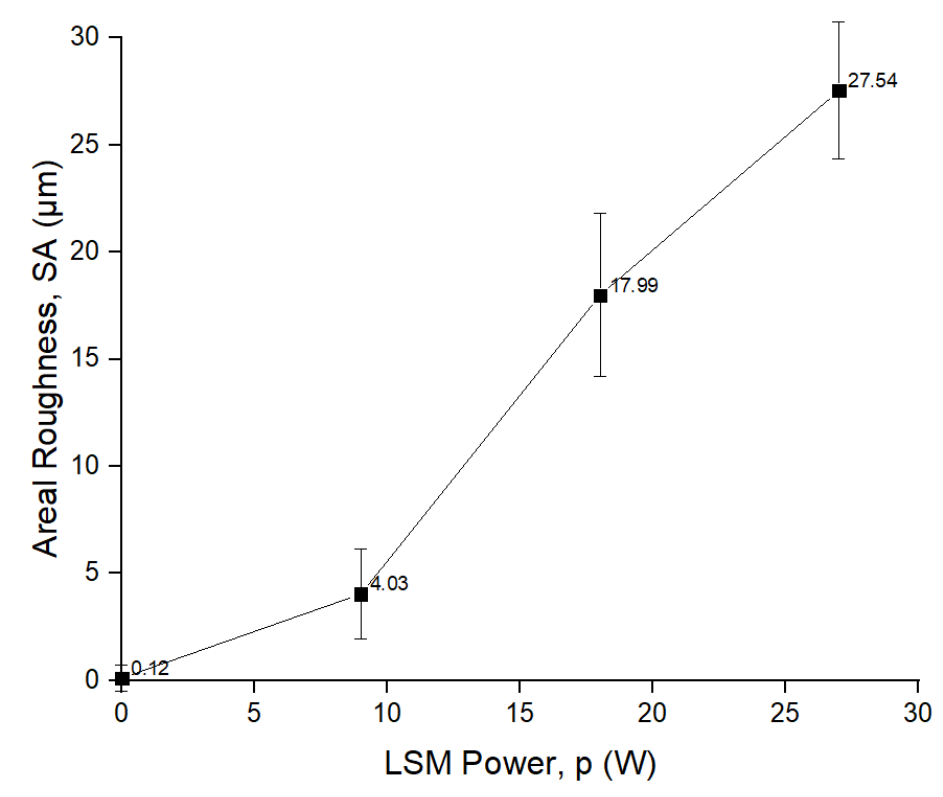

Figure 4. Effect of variable LSM laser power on surface roughness 
Table 6. Surface topography of modified titanium alloy under variable power with dimension of $648 \mu \mathrm{m}$ x $646 \mu \mathrm{m}$

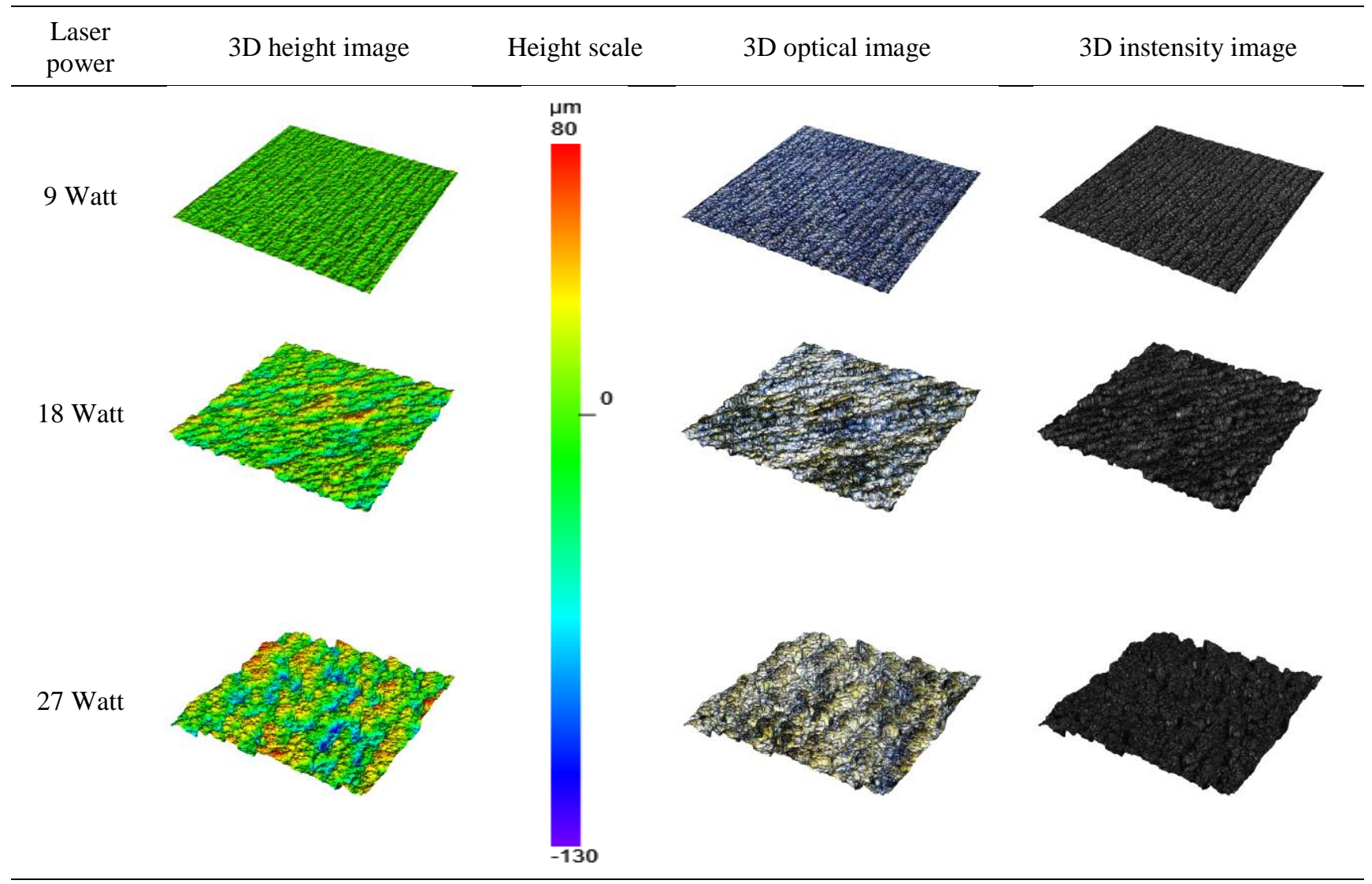

\section{Effect of Surface Roughness on Heating Temperature}

In the next stage of this study, a laser heating experiment was conducted based on the modified sample during LSM earlier. Figure 5 demonstrates the temperature profile for each sample when radiated with the variable power of laser heating. The samples were heated rapidly for 60 seconds. It should be noted that the laser beam was ceased at $t=60 \mathrm{~s}$ and the cooling phase started immediately after that period.

When the specimen with a low roughness value was radiated, it required a longer time to boost the temperature than the one with a rough surface. For instance, when heated with $100 \mathrm{~W}$ laser heating, the non-modified surface took approximately $20 \mathrm{~s}$ more than other modified surfaces to increase the temperature. The rapid rise of temperature was related to a rough surface's ability to absorb more laser energy compared to a flat surface when heated with similar laser power. The result obtained was in good agreement with the study reported by Quazi et al., who stated higher energy absorption can be attained by modifying the surface geometry through increasing the surface roughness [17].

Moreover, when radiating a flat metal surface, a high laser power is required to compensate for low energy efficiency since there is more energy wasted to the ambient compared to the absrobed energy. Hence, a surface with a high value of roughness could significantly increase energy efficiency. This is because, there is no need for a high power to perform laser heating on metal since the low laser power can obtain the same result with a modified surface. This has been reported by D. Bergström [18], who claimed that material with textured surface was found to be one of the main contributing factors in enhancing the laser energy efficiency. He also added that the mechanism still depends on other factors such as material and laser wavelength. Hence, surface roughness is definitely a factor that could influence the laser absorptivity, which resulting in high energy efficiency.

Additionally, the trend of temperature gradients obtained could also be correlated with the laser heating power. This situation is visible in the profile, at which the temperature gradient of the sample heated with high power is much steeper than the lower power. This is because, when heated with $140 \mathrm{~W}$, the temperature in the irradiated region exceeds the melting point of titanium alloy and hence nulling the effect of surface modification. It was stated in the earlier work of Xie, who discovered that the absorptivity of metals increases when melting temperatures are reached [19]. The surface of the workpiece melts in a very short time after the high-power laser irradiation begins. On the other hand, heating the sample with $100 \mathrm{~W}$ laser power did not melt the titanium alloy since the laser energy is much lower to melt the surface layer. 


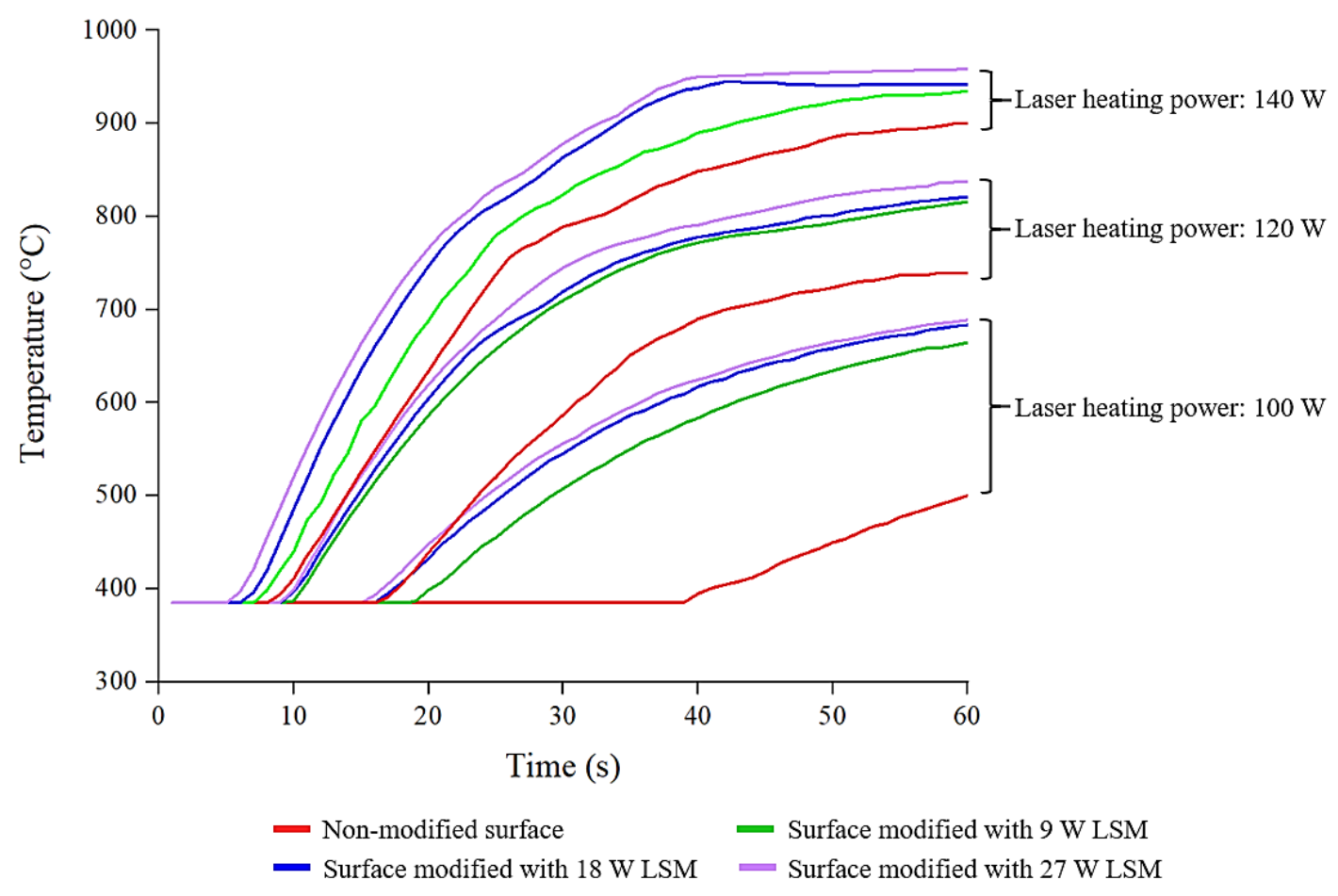

Figure 5. Temperature profile of laser heating on difference surface roughness

Figure 6 shows the relationship between the surface roughness and the maximum temperature measured when heated with variable laser power. The diagram represents almost the same trend for all modified surface when heated with laser. The temperature measured on the modified surface increased significantly when heated with the lowest laser power, $9 \mathrm{~W}$, and remained enhance as the laser power increased. This shows that the temperature increases when the laser radiates a high surface roughness. For instance, during laser heating with $100 \mathrm{~W}$ laser power, the maximum temperature, $690{ }^{\circ} \mathrm{C}$, was recorded by the sample with the highest surface roughness value, $27.54 \mu \mathrm{m}$. It reflects that the laser energy absorption was improved up to $38 \%$ compared to the non-modified surface. The reason for this is that when a laser radiates a rough and textured surface, the laser energy will be scattered over a larger surface area and increase the absorptivity into the material [20]. The energy absorbed into the material is then converted to heat energy, concluding the heating temperature increment. The observation agrees with Maina, who reported that fiber laser's absorption rate could be enhanced when radiated on an undulate and rough surface [21]. Conclusively, a higher surface roughness by laser surface modification corresponds to more energy absorption and leads to higher temperature during laser heating.

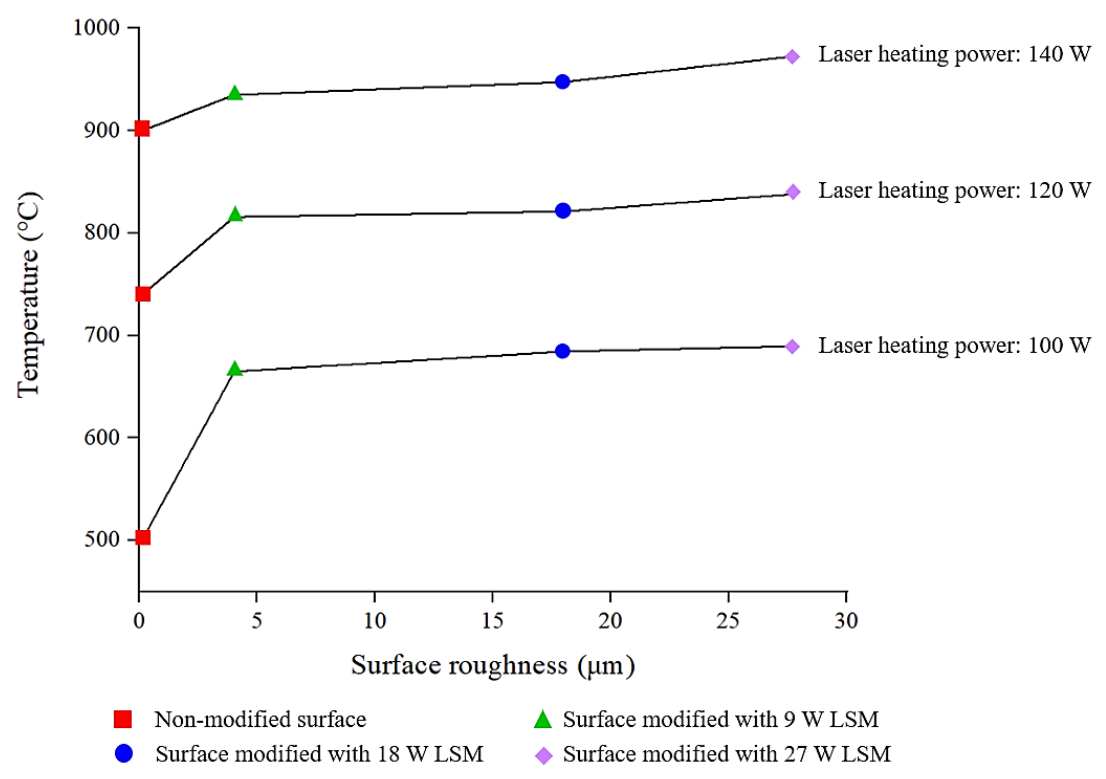

Figure 6. Effect of surface roughness on maximum temperature when heated with different laser power 
On the other hand, when a laser radiates onto a non-modified surface, more laser energy is reflected away towards the atmosphere compared to the energy absorbed into the material. Hence, less energy will be converted to heat and decrease the temperature measured during the laser heating process. As a result, the laser heating temperature is higher when radiating on a rough surface than the surface with a small value of roughness.

\section{CONCLUSIONS}

In the present study, experimental investigation, and analysis of the laser surface modification on titanium alloy were made. The effect of laser power was analyzed on the modified surface layer. Besides that, the effect of the modified surface roughness towards the temperature of laser heating was studied. From the experimental results, the following conclusions can be drawn:

1. Applying a high laser power during laser surface modification process results in increasing surface roughness value.

2. Increasing the surface roughness of titanium alloy by laser surface modification method could effectively enhance the laser heating temperature compared to the non-modified surface layer.

The experimental results of the current research will be useful guidelines for further work for analyzing other surface characteristic features that can enhance optical properties of the material such as coating formation.

\section{ACKNOWLEDGMENTS}

The authors would like to thank the Ministry of Education Malaysia and University Malaysia Pahang for the financial support given through research grant RDU192608 (RACER/1/2019/TK03/UMP//3), RDU1903118, and PGRS200305. Also, laboratory facilities support such as 3D measuring laser microscope from Faculty of Manufacturing and Mechatronic Engineering Technology of University Malaysia Pahang, are gratefully acknowledged.

\section{REFERENCES}

[1] Q. Zhang, J. Chen, H. Tan, X. Lin, and W.-d. Huang, "Microstructure evolution and mechanical properties of laser additive manufactured Ti-5Al-2Sn-2Zr-4Mo-4Cr alloy," Transactions of Nonferrous Metals Society of China, vol. 26, no. 8, pp. 20582066, 2016/08/01/ 2016, doi: https://doi.org/10.1016/S1003-6326(16)64300-5.

[2] X. F. Zhou, J. A. Duan, F. Zhang, and S. S. Zhong, "The Study on Mechanical Strength of Titanium-Aluminum Dissimilar Butt Joints by Laser Welding-Brazing Process," Materials, vol. 12, no. 5, Mar 2019, Art no. 712, doi: 10.3390/ma12050712.

[3] J. Liu, H. Liu, X.-L. Gao, and H. Yu, "Microstructure and mechanical properties of laser welding of Ti6Al4V to Inconel 718 using Nb/Cu interlayer," Journal of Materials Processing Technology, vol. 277, p. 116467, 2020.

[4] M. M. Quazi et al., "Current research and development status of dissimilar materials laser welding of titanium and its alloys," (in English), Opt. Laser Technol., Review vol. 126, p. 36, Jun 2020, Art no. 106090, doi: 10.1016/j.optlastec.2020.106090.

[5] H. R. Abedi and M. H. Gollo, "An experimental study of the effects of surface roughness and coating of $\mathrm{Cr} 2 \mathrm{O} 3$ layer on the laser-forming process," Optics \& Laser Technology, vol. 109, pp. 336-347, 2019.

[6] M. V. Zhidkov, T. N. Vershinina, O. A. Golosova, S. I. Kudryashov, and A. A. Ionin, "Surface texturing of steel by femtosecond laser and accompanying structure/phase transformations," (in English), Opt. Laser Technol., Article vol. 131, p. 7, Nov 2020, Art no. 106370, doi: 10.1016/j.optlastec.2020.106370.

[7] S. J. Won and H. S. Kim, "Effects of laser parameters on morphological change and surface properties of aluminum alloy in masked laser surface texturing," Journal of Manufacturing Processes, vol. 48, pp. 260-269, 2019.

[8] L. Ramasamy, M. Quazi, M. Ishak, M. Aiman, A. Zafiuddin, and A. Qaban, "Formation of colours on SS304L stainless steel induced by laser colouring," IOP Conference Series: Materials Science and Engineering, vol. 1078, p. 012015, 02/01 2021, doi: 10.1088/1757-899X/1078/1/012015.

[9] S. Roduan, J. A Wahab, M. Aiman, A. Q. Zaifuddin, M. Salleh, and M. Ishak, "Effect of laser loop on surface morphology of copper substrate and wettability of solder joint," IOP Conference Series: Materials Science and Engineering, vol. 701, p. 012040, 12/19 2019, doi: 10.1088/1757-899X/701/1/012040.

[10] Y. Oshida, Bioscience and bioengineering of titanium materials. Elsevier, 2010.

[11] C. Earl, J. Castrejón-Pita, P. Hilton, and W. O’Neill, "The dynamics of laser surface modification," Journal of Manufacturing Processes, vol. 21, pp. 214-223, 2016.

[12] B. Mao, A. Siddaiah, Y. Liao, and P. L. Menezes, "Laser surface texturing and related techniques for enhancing tribological performance of engineering materials: A review," Journal of Manufacturing Processes, vol. 53, pp. 153-173, 2020.

[13] D. Bhaduri et al., "On design and tribological behaviour of laser textured surfaces," Procedia CIRP, vol. 60, pp. 20-25, 2017/01/01/ 2017, doi: https://doi.org/10.1016/j.procir.2017.02.050. 
[14] A. Sulaiman, M. Aiman, M. Quazi, M. Ishak, and T. Ariga, "Enhancement of mechanical properties of Copper Brazed by laser surface modification," in IOP Conference Series: Materials Science and Engineering, 2020, vol. 788, no. 1: IOP Publishing, p. 012012.

[15] F. Kaschel, M. Celikin, and D. Dowling, "Effects of laser power on geometry, microstructure and mechanical properties of printed Ti-6Al-4V parts," Journal of Materials Processing Technology, vol. 278, p. 116539, 2020.

[16] F. Fauzun, S. N. A. S. Ahmad, and I. Ismail, "Design of laser melting of tool steel for surface integrity enhancement," Jurnal Tribologi, vol. 22, pp. 18-31, 2019.

[17] M. M. Quazi, M. A. Fazal, A. S. M. A. Haseeb, F. Yusof, H. H. Masjuki, and A. Arslan, "Laser-based Surface Modifications of Aluminum and its Alloys," Critical Reviews in Solid State and Materials Sciences, vol. 41, no. 2, pp. 106-131, 2016/03/03 2016, doi: 10.1080/10408436.2015.1076716.

[18] D. Bergstrom, J. Powell, and A. Kaplan, "The absorption of light by rough metal surfaces —A three-dimensional ray-tracing analysis," Journal of Applied Physics, vol. 103, pp. 103515-103515, 06/01 2008, doi: 10.1063/1.2930808.

[19] J. Xie, A. Kar, J. A. Rothenflue, and W. P. Latham, "Temperature - dependent absorptivity and cutting capability of CO2, Nd: YAG and chemical oxygen-iodine lasers," Journal of Laser Applications, vol. 9, no. 2, pp. 77-85, 1997.

[20] A. Zaifuddin, M. Aiman, M. Quazi, M. Ishak, and T. Ariga, "Effect of laser surface modification (LSM) on laser energy absorption for laser brazing," in IOP Conference Series: Materials Science and Engineering, 2020, vol. 788, no. 1: IOP Publishing, p. 012013.

[21] M. R. Maina, Y. Okamoto, R. Inoue, S.-i. Nakashiba, A. Okada, and T. Sakagawa, "Influence of surface state in micro-welding of copper by Nd: YAG laser," Applied Sciences, vol. 8, no. 12, p. 2364, 2018. 